\title{
Uneven clustering and fuzzy logic based energy-efficient wireless sensor networks
}

\author{
Mohammed Adnan Altaha ${ }^{1}$, Ahmed Adil Alkadhmawee ${ }^{2}$, Wisam Mahmood Lafta ${ }^{3}$ \\ ${ }^{1}$ Department of Veterinary Public Health, College of Veterinary, Universitiy of Basrah, Basrah, Iraq \\ ${ }^{2}$ Department of English, College of Education for Human Sciences, Universitiy of Basrah, Basrah, Iraq \\ ${ }^{3}$ Department of Computer Science, Universitiy of Technology, Baghdad, Iraq
}

\begin{abstract}
Article Info
\section{Article history:}

Received Jul 17, 2021

Revised Dec 1, 2021

Accepted Dec 9, 2021

\section{Keywords:}

Cost bounded

Energy threshold

Fuzzy logic

IDA star algorithm

Uneven clustering

ABSTRACT

Clustering is the fundamental issue in terms of ensuring long-term operation of wireless sensor networks (WSNs). The problem of hot spots remains the most prominent research challenge relating to the design of energy-efficient clustering algorithm. This paper proposed a protocol, namely an uneven clustering and fuzzy logic-based energy-efficient (UCFLEE), for prolonging network lifetime. Depending on the communication distance, the UCFLEE protocol divides the network into uneven clusters for suppressing the hot spot problem. The fuzzy logic selects the optimal cluster head in accordance with certain parameters. The advocated method adopts a dynamic energy threshold to chnage the cluster head. The UCFLEE protocol is dependent on the iterative deepening A (IDA) star algorithm for identifying the routing path from the cluster heads to the base station. The IDA-star method is reliant upon a cost bounded method to select the optimal solution for the base station. The UCFLEE protocol is tested and subsequently contrasted with other protocols. The results obtained from the UCFLEE protocol enable an energy consumption equilibrium, eradicates the hot spot challenge, while also attaining maximum network lifetime.
\end{abstract}

This is an open access article under the CC BY-SA license.

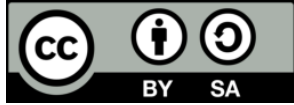

\section{Corresponding Author:}

Mohammed Adnan Altaha

Department of computer sciences, College of Veterinary, Universitiy of Basrah

Basrah, Iraq

Email: mohammed.altaha@uobasrah.edu.iq

\section{INTRODUCTION}

Wireless sensor networks (WSN) is a significant and evolving form of communications network that may be adopted in order to sense numerous environmental and physical parameters (for example humidity, smoke, pressure and temperature) [1], [2]. A WSN is formed from integrated and miniaturised sensor nodes, embedded systems, wireless communications, in addition to other technologies [3]. WSN nodes have limited energy resource capabilities, whole typically being unreachable and unmanned [4]-[6]. Accordingly, conserving energy and the means of identifying an energy-efficient strategy for extending network lifetime have emerged as fundamental challenges in relation to WSN design.

Clustering is the most prominent issue in terms of accommodating the limited resources of sensor nodes in WSNs, particularly in relation to energy capacity [7], [8]. Clustering aims to diminish the network's energy consumption by gathering those nodes possessing equivalent characteristics, or those nodes in close proximity, to form clusters. The base station (BS) elects the cluster head (CH) per cluster so as to manage the cluster activities. The $\mathrm{CHs}$ are responsible for aggregating the sensed data in order to measure physical phenomenon of interest from their member nodes. Subsequently, the $\mathrm{CHs}$ forwards the aggregated data directly to the BS or via relay CHs [8], [9]. 
Numerous clustering protocols have been presented with the aim of lengthening the network lifespan via optimising energy management. Heinzelman et al. [10], the authors designed a first clustering protocol, namely low energy adaptive clustering hierarchy $(\mathrm{LEACH})$, which adapted the network to evenly share an energy load among the nodes. The LEACH protocol formed nodal clusters and adopted a local node as a head of members per cluster. The authors proposed a LEACH-C as the protocol, which enhances the performance of the LEACH protocol [11]. This protocol involves the BS selecting various CHs and placing each $\mathrm{CH}$ at the centre of a cluster. Liang et al. [12], the authors proposed the PSO-C protocol to provide the WSN with a higher lifetime. The proposed scheme applies the PSO algorithm as a means of calculating the optimal $\mathrm{CH}$ as well as the fitness function, thus optimising the WSN's energy efficiency and reducing consumption. The aforementioned protocols used the single communication approach between the $\mathrm{CHs}$ and the BS. The CHs suffer from preliminary death when they are located at great a distance from the BS [13], [14].

Cengiz and Dag [15] presented a novel protocol called multi-hop low energy fixed clustering algorithm (MLEFCA), as a means of limiting the energy dissipation. The MLEFCA protocol offers a multihop routing to the $\mathrm{BS}$ via electing the closer neighbour $\mathrm{CH}$ as a relay node. Selvi et al. [16], the researchers proposed the honey bee optimization (HBO) technique in order to balance energy consumption, through selecting the optimum routing path. The HBO technique utilised the enhanced k-means algorithm to form the clusters, in addition to the $\mathrm{HBO}$ algorithm to determine the path to the BS. The balanced residual energyLEACH (BRE-LEACH) is an original protocol introduced to expand network lifetime [17]. The BRE$\mathrm{LEACH}$ protocol depends on the remaining energy to select the best $\mathrm{CH}$. This proposed approach selects the optimal $\mathrm{CH}$ as the root $\mathrm{CH}$. The farthest $\mathrm{CHs}$ used the multi-hop path to aggregate data at the root $\mathrm{CH}$. In multi-hop wireless communication, the CHs nearest to the BS aggregate the data packet from the farther $\mathrm{CHs}$. The CHs nearest to the BS are exerting additional energy compared with other $\mathrm{CHs}$, as a result of data dissemination and heavy traffic. This creates a hot spot problem in WSNs and swifter expenditure of energy by the $\mathrm{CHs}$ [18]-[21]. Consequently, selecting the $\mathrm{CH}$ and resolving the hot spot problem are the foremost challenges to account for while designing energy efficient clustering.

For load balance achievement and mitigation of the hot spot problem, this paper advocates a protocol named uneven clustering and fuzzy logic-based energy-efficient (UCFLEE). Based on the communication distance, the UCFLEE protocol divides the network area into two sectors of different sizes. The smaller sector is situated in closer proximity to the BS, whereas the larger sector is located farther away from the BS. The larger sector is further divided into equal size sectors in accordance with the communication distance. The proposed protocol utilises fuzzy logic as a means of identifying optimal CHs. The $\mathrm{CH}$ change is dependent on the energy threshold to equally distribute the $\mathrm{CHs}$ ' roles between the nodes. The proposed scheme developed the iterative deepening A (IDA) algorithm to establish the multi-hop path to the BS.

The remainder of this paper is as shown in: section 2 describes the system model. The UCFLEE protocol is discussed with all its details in section 3, while section 4 details the UCFLEE protocol's overall performance following the completion of the simulation trials. In section 6 , the conclusions obtained from this paper are presented.

\section{SYSTEM MODEL}

\subsection{Network model}

The network comprises of numerous sensors that are disseminated randomly throughout the network. The following properties describe the network sensors: i) The BS is immobile and aware of the nodes locations; ii) The BS used a sufficient amount of resources to manage the network; iii) Nodes are static, with each sensor having a unique identification while also being unaware of the location; and iv) Initially, nodes have the same amount of appropriated energy, computation capabilities and communication power.

\subsection{Energy model}

The node battery is consumed significantly via the data communication process (data transmission and data reception). The first radio model is used to compute the energy consumed by the nodes [11]. The energy consumed to transmit $\left(E_{c-t x}\right)$ and receive $\left(E_{c-R x}\right)$ n-bit data over communication distance $\mathrm{d}$ metres may be calculated by (1)-(3):

$$
\begin{aligned}
& E_{c-t x}(n, d)=\left\{\begin{array}{c}
n \times E_{\text {elec }}+n \times \epsilon_{f s} \times d^{2} \\
n \times E_{\text {elec }}+n \times \epsilon_{m p} \times d^{2}
\end{array}\right\} d \leq d_{\text {Threshold }} \\
& d>d_{\text {Threshold }} \\
& E_{c-R x}(n, d)=n \times E_{\text {eleec }}
\end{aligned}
$$




$$
E_{c-t o t a l}=E_{c-t x}(n, d)+E_{c-R x}(n, d)
$$

$E_{\text {elec }}$ indicates the electronic circuit's energy consumption, while either $\epsilon_{f s}$ (free space channel)or $\epsilon_{m p}$ (multipath fading) denote the transmitter amplifier's energy consumption. Either $\epsilon_{f s}$ or $\epsilon_{m p}$ are used depending on the communication distance $(d)$ between the nodes. $d_{\text {Threshold }}$ refers to the threshold distance, which may be determined in (4):

$$
d_{\text {Threshold }}=\frac{\epsilon_{f s}}{\epsilon_{m p}}
$$

\section{PROPOSED UCFLEE PROTOCOL}

\subsection{Sector formation phase}

The BS partitions the network area into two sectors of varying size. The smaller sector is situated nearer to the BS, whereas the larger sector is located at some distance from the BS. According to (5), the BS determined the smaller sector's size, where $\mathrm{R}$ denotes the maximum range of communication distance. The clusters' small size averts the premature death of those nodes in closer proximity to the BS, therefore resolving the hot spots issue. The larger sector is that beyond the smaller sector. The BS divided the larger sector into sub-sectors, with each sub-sector's size being equal to R. In the network area, each sector is partitioned into clusters of equal width. Each cluster's width is always equal to the value of sector smaller $_{\text {in (5). }}$ Figure 1. presents the sector formation phase. Algorithm 1 clarifies all of the steps involved in the sectors' formation.

$$
\text { sector }_{\text {smaller }}=\frac{R}{2}
$$

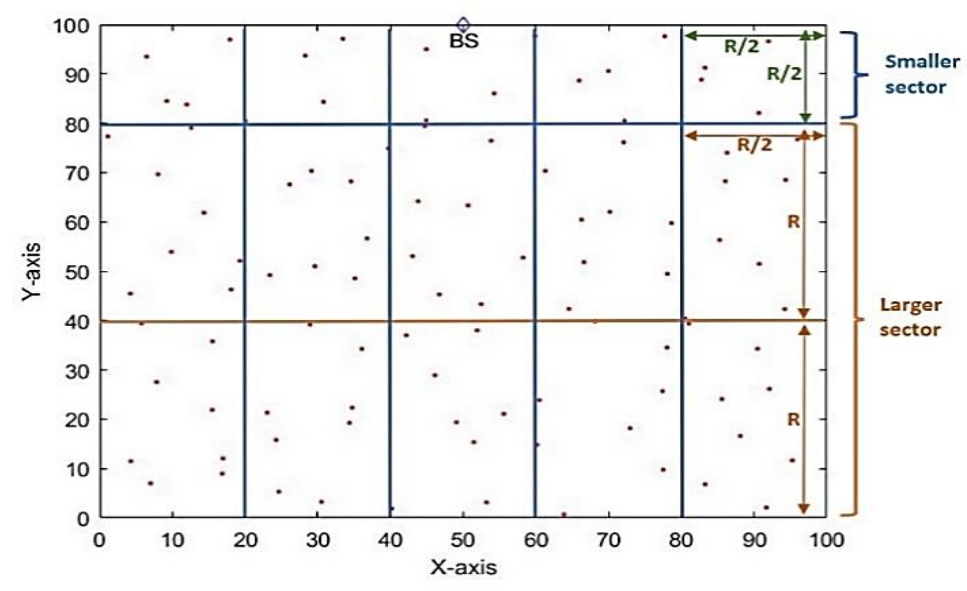

Figure 1. Sector formation phase

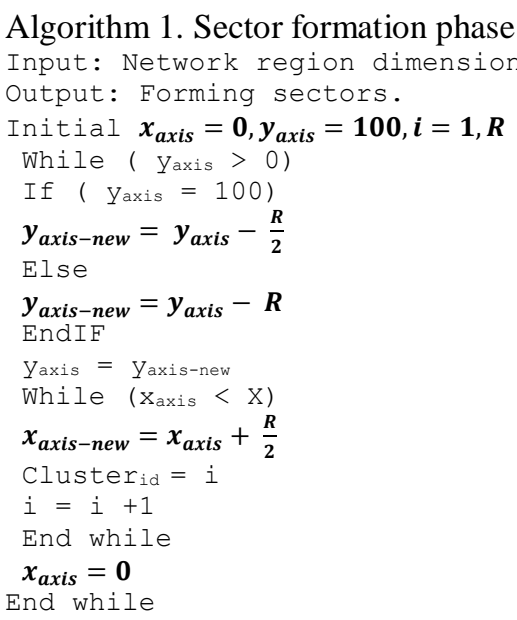




\subsection{CH selection phase}

The BS utilises the fuzzy logic (FL) model in order to select the optimal CH per cluster. Two input variables, namely the distance to BS as well as residual energy, are given to the FL model, while the output variable is produced, namely $\mathrm{CH}$ chance. Table 1 presents the tabulation of the membership functions for the input and output variables. The value range of the distance to BS as well as residual energy parameters are [0-120] and [0-0.5] respectively, as presented in Figures 2 and 3. The output variable's value range is [0-1], as evidenced in Figure 4.

In the FL model, every input variable's value is transformed into the linguistic variable via the fuzzification process. Subsequently, if-then rules may be applied in relation to the linguistic variables as a means of connecting the input parameters and relevant output variables. A total of $25\left(5^{2}\right)$ if-then rules are performed depending on two input variables, as Table 2 clarifies. Lastly, by applying the centre of area method, the defuzzification process enables the output linguistic variables to be transformed into the output value [22].

The BS uses the dynamic energy threshold (DT) to chnage the $\mathrm{CH}$ in each cluster. According to (6), the BS calculates the $D T$ value at the conclusion of each round. The $\mathrm{CH}$ changes whether its residual energy was below the DT value. Algorithm 2 describes the $\mathrm{CH}$ selection method.

$$
\mathrm{DT}=\frac{1}{N} * E_{\text {total }} *\left(1-\frac{r_{\text {current }}}{R_{\text {estimated }}}\right)
$$

$E_{\text {total }}$ indicates the total energy during the network's initial operation. The $r_{\text {current }}$ pertains to the numeral of the current round, while $R_{\text {estimated }}$ refers to the number of estimated rounds until expiry of all of the network's nodes. $N$ denotes the total sensor number. As shown in (7) represents the $R_{\text {estimated value, }}$ when $E_{\text {Current }}$ is the current round's energy consumption:

$$
R_{\text {estimated }}=\frac{E_{\text {total }}}{E_{\text {current }}}
$$

Table 1. Membership function for the proposed protocol

\begin{tabular}{cc}
\hline Variable & Membership function \\
\hline Distance to BS & Very Close $\left(\mathrm{D}_{\mathrm{VC}}\right)$, Close $\left(\mathrm{D}_{\mathrm{C}}\right)$, Medium $\left(\mathrm{D}_{\mathrm{M}}\right)$, Far $\left(\mathrm{D}_{\mathrm{F}}\right)$ Very Far $\left(\mathrm{D}_{\mathrm{VF}}\right)$ \\
Residual Energy & Very High $\left(\mathrm{RE}_{\mathrm{VH}}\right)$, High $\left(\mathrm{RE}_{\mathrm{H}}\right)$, Medium $\left(\mathrm{RE}_{\mathrm{M}}\right)$, Low $\left(\mathrm{RE}_{\mathrm{L}}\right)$, Very Low $\left(\mathrm{RE}_{\mathrm{VL}}\right)$ \\
CH Chance & Very Strong $\left(\mathrm{C}_{\mathrm{VS}}\right)$, Strong $\left(\mathrm{C}_{\mathrm{S}}\right)$, Medium $\left(\mathrm{C}_{\mathrm{M}}\right)$, Weak $\left(\mathrm{C}_{\mathrm{W}}\right)$, Very Weak $\left(\mathrm{C}_{\mathrm{VW}}\right)$ \\
\hline
\end{tabular}

\begin{tabular}{|c|c|c|c|}
\hline No. & Residual Energy & Distance to BS & Chance \\
\hline 1 & $\mathrm{RE}_{\mathrm{VL}}$ & $\mathrm{D}_{\mathrm{VF}}$ & $\mathrm{C}_{\mathrm{VW}}$ \\
\hline 2 & $R E_{V L}$ & $\mathrm{D}_{\mathrm{F}}$ & $\mathrm{C}_{\mathrm{VW}}$ \\
\hline 3 & $\mathrm{RE}_{\mathrm{VL}}$ & $D_{M}$ & $\mathrm{C}_{\mathrm{VW}}$ \\
\hline 4 & $\mathrm{RE}_{\mathrm{VL}}$ & $\mathrm{D}_{\mathrm{C}}$ & $\mathrm{C}_{\mathrm{VW}}$ \\
\hline 5 & $\mathrm{RE}_{\mathrm{VL}}$ & $\mathrm{D}_{\mathrm{VC}}$ & $\mathrm{C}_{\mathrm{W}}$ \\
\hline 6 & $\mathrm{RE}_{\mathrm{L}}$ & $\mathrm{D}_{\mathrm{VF}}$ & $\mathrm{C}_{\mathrm{VW}}$ \\
\hline 7 & $\mathrm{RE}_{\mathrm{L}}$ & $\mathrm{D}_{\mathrm{F}}$ & $\mathrm{C}_{\mathrm{W}}$ \\
\hline 8 & $\mathrm{RE}_{\mathrm{L}}$ & $\mathrm{D}_{\mathrm{M}}$ & $\mathrm{C}_{\mathrm{W}}$ \\
\hline 9 & $\mathrm{RE}_{\mathrm{L}}$ & $\mathrm{D}_{\mathrm{C}}$ & $\mathrm{C}_{\mathrm{M}}$ \\
\hline 10 & $\mathrm{RE}_{\mathrm{L}}$ & $\mathrm{D}_{\mathrm{VC}}$ & $\mathrm{C}_{\mathrm{M}}$ \\
\hline 11 & $\mathrm{RE}_{\mathrm{M}}$ & $\mathrm{D}_{\mathrm{VF}}$ & $\mathrm{C}_{\mathrm{W}}$ \\
\hline 12 & $\mathrm{RE}_{\mathrm{M}}$ & $\mathrm{D}_{\mathrm{F}}$ & $\mathrm{C}_{\mathrm{W}}$ \\
\hline 13 & $\mathrm{RE}_{\mathrm{M}}$ & $D_{M}$ & $\mathrm{C}_{\mathrm{M}}$ \\
\hline 14 & $\mathrm{RE}_{\mathrm{M}}$ & $\mathrm{D}_{\mathrm{C}}$ & $\mathrm{C}_{\mathrm{M}}$ \\
\hline 15 & $\mathrm{RE}_{\mathrm{M}}$ & $\mathrm{D}_{\mathrm{VC}}$ & $\mathrm{C}_{\mathrm{S}}$ \\
\hline 16 & $\mathrm{RE}_{\mathrm{H}}$ & $\mathrm{D}_{\mathrm{VF}}$ & $\mathrm{C}_{\mathrm{M}}$ \\
\hline 17 & $\mathrm{RE}_{\mathrm{H}}$ & $\mathrm{D}_{\mathrm{F}}$ & $\mathrm{C}_{\mathrm{M}}$ \\
\hline 18 & $\mathrm{RE}_{\mathrm{H}}$ & $\mathrm{D}_{\mathrm{M}}$ & $\mathrm{C}_{\mathrm{S}}$ \\
\hline 19 & $\mathrm{RE}_{\mathrm{H}}$ & $\mathrm{D}_{\mathrm{C}}$ & $\mathrm{C}_{\mathrm{S}}$ \\
\hline 20 & $\mathrm{RE}_{\mathrm{H}}$ & $\mathrm{D}_{\mathrm{VC}}$ & $\mathrm{C}_{\mathrm{VS}}$ \\
\hline 21 & $\mathrm{RE}_{\mathrm{VH}}$ & $\mathrm{D}_{\mathrm{VF}}$ & $\mathrm{C}_{\mathrm{S}}$ \\
\hline 22 & $\mathrm{RE}_{\mathrm{VH}}$ & $\mathrm{D}_{\mathrm{F}}$ & $\mathrm{C}_{\mathrm{S}}$ \\
\hline 23 & $\mathrm{RE}_{\mathrm{VH}}$ & $D_{M}$ & $\mathrm{C}_{\mathrm{VS}}$ \\
\hline 24 & $\mathrm{RE}_{\mathrm{VH}}$ & $\mathrm{D}_{\mathrm{C}}$ & $\mathrm{C}_{\mathrm{VS}}$ \\
\hline 25 & $\mathrm{RE}_{\mathrm{VH}}$ & $\mathrm{D}_{\mathrm{VC}}$ & $\mathrm{C}_{\mathrm{VS}}$ \\
\hline
\end{tabular}

Table 2. Fuzzy rules for the proposed protocol 


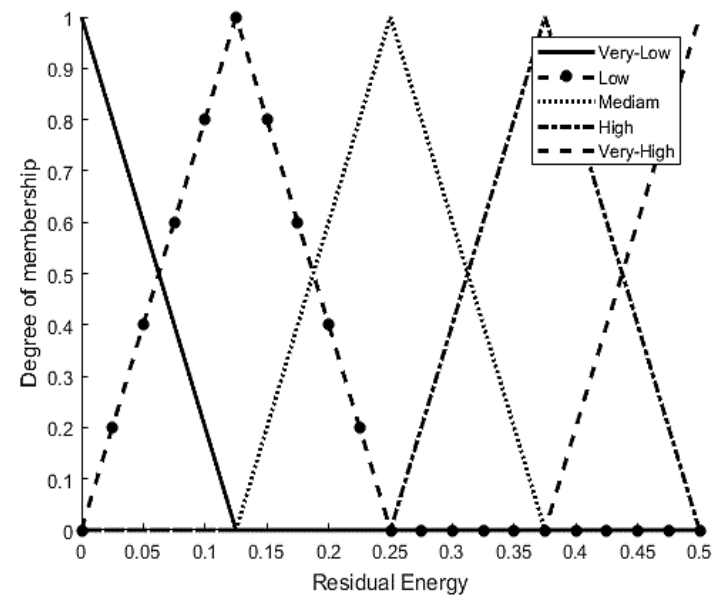

Figure 2. The member function for distance to BS

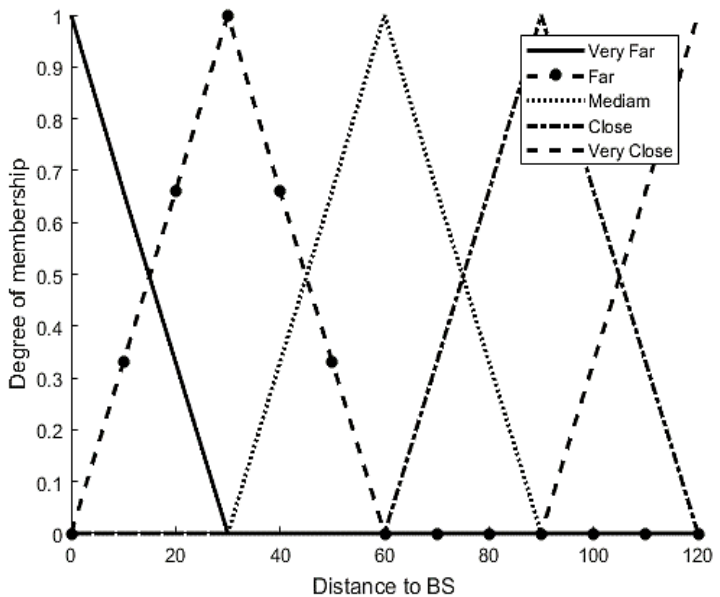

Figure 3. The member function for residual energy

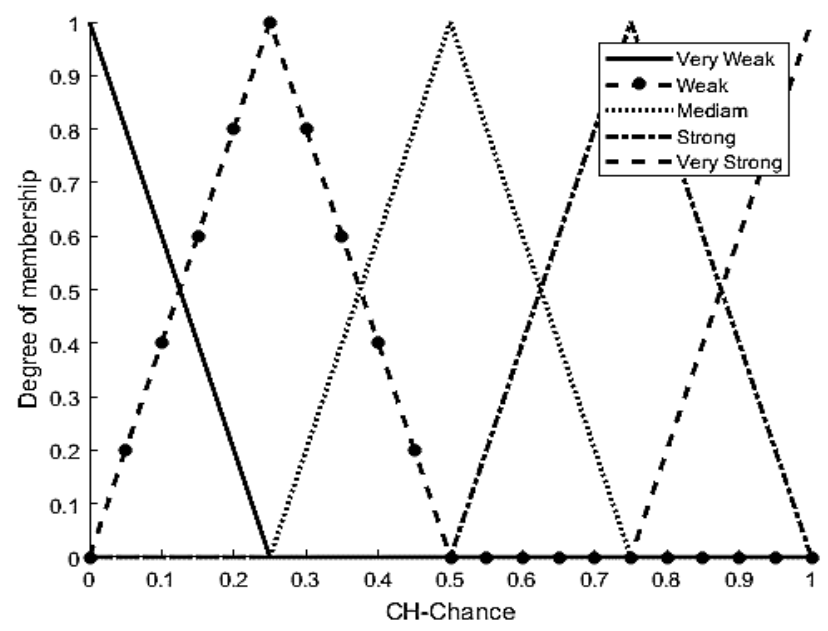

Figure 4. The member function for the output variable

Algorithm 2. CH selection method

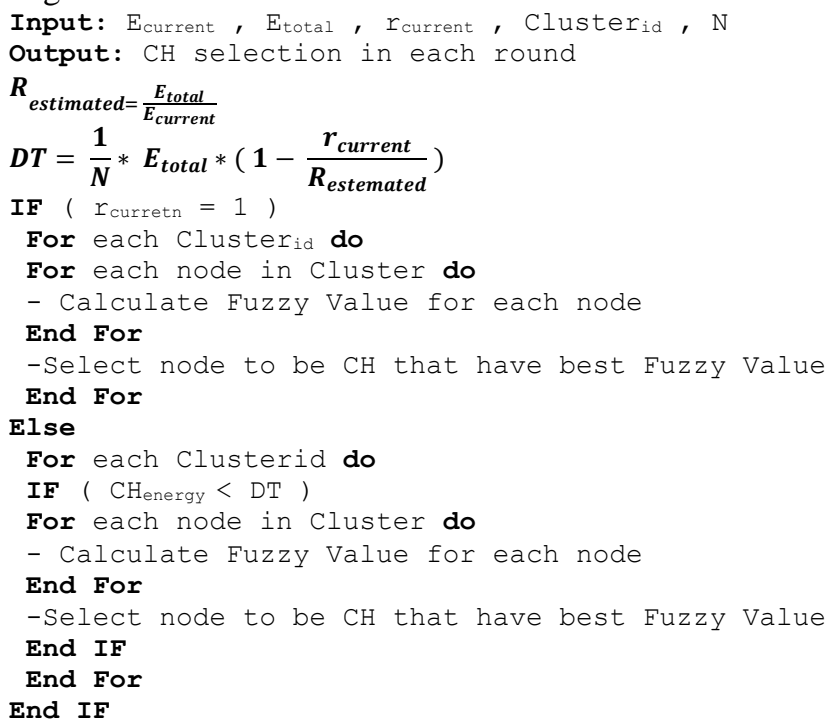




\subsection{Data routing phase}

The BS adopts the iterative deepening A* (IDA-star) method to discover the optimal multi-hop path from the CHs. The IDA-star method enables the establishment of the shortest path with the least memory usage based on iterative deepening [23]-[25]. Furthermore, the IDA-star algorithm determines the evolution function of cluster heads $f\left(\mathrm{CH}_{s}\right)$ in accordance with (8). The IDA-star algorithm is reliant upon two parameters to calculate the $\mathrm{f}$ value, namely energy level $\left(E_{C H}\right)$ and the distance to the $\mathrm{BS}\left(d_{C H-B S}\right)$. The IDAstar algorithm uses the cost bounded ( Cost $_{\text {bounded }}$ ) value to determine the optimal solution to the BS, which is expressed by (9).

$$
\begin{aligned}
& f\left(\mathrm{CH}_{S}\right)=d_{C H-B S}+E_{C H} \\
& \text { Cost }_{\text {bounded }}=\text { smallest }(f(C H))
\end{aligned}
$$

The value of Cost $_{\text {bounded }}$ is the $\mathrm{f}$ value of the $\mathrm{CH}$ for the initial state. Per new level, the Cost $\mathrm{bounded}_{\text {b }}$ is the smallest $\mathrm{f}$ value among all the $\mathrm{CHs}$ that exceeded the previous Cost $_{\text {bounded }}$ of the preceding level. The $\mathrm{CH}$ collects data from the sensor nodes. Subsequently, the $\mathrm{CH}$ with an $\mathrm{f}$ value that exceeded the cost bounded is added to the list called the 'previous list'. In this previous list, the $\mathrm{CH}$ with a larger f-value is added to the optimal path list, enabling its selection as the next hop. The IDA star continues until the optimal path has been guaranteed based on attaining the BS.

Having completed the routing path, the $\mathrm{CH}$ that has the information sends the route request (RREQ) message to the next $\mathrm{CH}$ in the optimal path. The $\mathrm{CH}$ waits for the route reply (RREP) message. Having delivered the RREP message, the information is sent to the next $\mathrm{CH}$. This process repeats from the next $\mathrm{CH}$ in the routing path, until the information has been delivered to the BS. Following each round, the BS checks the possibility of the current path sending further information or not, by comparing the energy per $\mathrm{CH}$ that exists in this path with the DT value. If the DT value exceeds the energy of $\mathrm{CH}$, then the BS adopts the FL model to identify the new $\mathrm{CH}$ in the cluster.

\section{PERFORMANCE EVALUATION}

The UCFLEE protocol's performance is evaluated by conducting simulation experiments. The simulation was undertaken utilising the MATLAB environment. 100 nodes were spread to the sensing region $100 \mathrm{~m} * 100 \mathrm{~m}$. The precise BS position was $100 \mathrm{~m} * 50 \mathrm{~m}$ of the network area. Table 3 presents further details of all the adopted simulation parameters. The proposed UCFLEE is compared with two widely recognised clustering protocols, namely BRE-LEACH [17] and PSO-C [12]. All protocols' performance analyses are informed by the evaluation variables, for example network lifetime and total residual energy per round. The performance of the UCFLEE protocol, BRE-LEACH and PSO-C may be described as follows, depending on the above factors.

Table 3. The simulation parameters of WSNs

\begin{tabular}{cc}
\hline Parameter & Value \\
\hline Area & $100 \mathrm{~m} * 100 \mathrm{~m}$ \\
$\mathrm{~N}$ & 100 nodes \\
$\boldsymbol{R}$ & $40 \mathrm{~m}$ \\
Position of BS & $100 \mathrm{~m} * 50 \mathrm{~m}$ \\
Initial amount of energy & $0.5 \mathrm{~J}$ \\
Data Packet & $4000 \mathrm{bit}$ \\
$\in_{\boldsymbol{m} \boldsymbol{p}}$ & $0.13 \mathrm{bit} / \mathrm{m}^{4}$ \\
$\boldsymbol{E}_{\text {elec }}$ & $50 \mathrm{~nJ} / \mathrm{bit}$ \\
$\epsilon_{\text {fs }}$ & $10 \mathrm{pJ} / \mathrm{bit} / \mathrm{m}^{2}$ \\
\hline
\end{tabular}

\subsection{Network lifetime}

The time interval between beginning the network operation to the death of the last node is represented as the network lifetime [26]. Figure 5 presents the network lifetime performance for the UCFLEE protocol as well as other protocols. This figure evidences that for BRE-LEACH and PSO-C, every node had died by 5000 and 6739 rounds respectively. Contrastingly, for the UCFLEE protocol, only 53 nodes died at 9000 rounds. Therefore, the UCFLEE approach contributes to lengthening the network lifetime to a greater extent than the BRE-LEACH and PSO-C protocols, by $64 \%$ and 56\% respectively. The DT concept to alter the CHs and the FL model in order to select the optimal CHs is the principal reason for the UCFLEE protocol being more effective than other related protocols with regard to the network lifetime. 


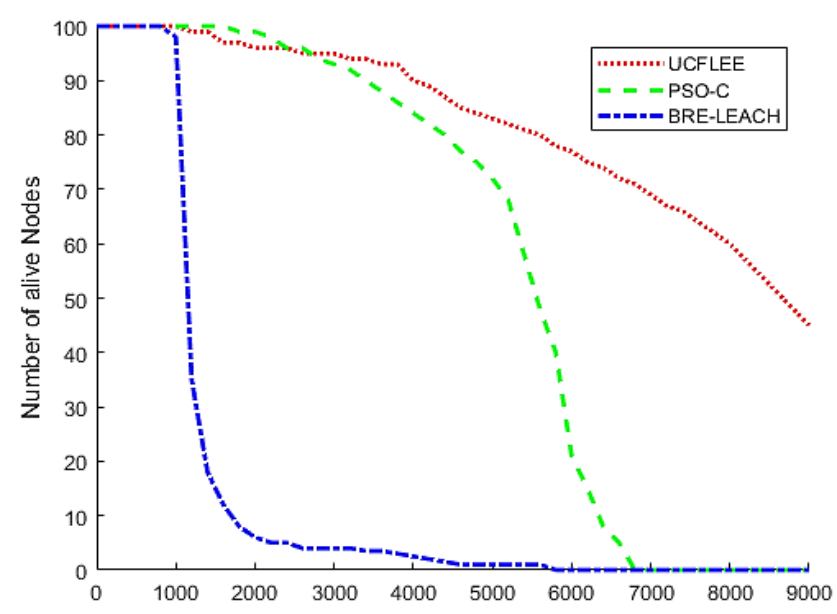

Figure 5. The network life time performance

\subsection{Residual energy}

Figure 6 presents the results of the total residual energy for the three approaches. After 7000 rounds, the energy in BRE-LEACH and PSO-C is completely consumed, whereas the proposed protocol preserves over $23 \%$ of its energy at 7000 rounds. With the UCFLEE strategy, the nodes' energy is depleted more slowly compared with other protocols, meaning that it enables effective conservation of the nodes' remaining energy. The DT contributes to continuing the $\mathrm{CH}$ for multiple rounds without change and distributing the traffic load between the nodes, thus saving greater energy. Moreover, the Cost ${ }_{\text {bounded }}$ in IDA-star facilitated the diminishing of the nodes' traffic load by expanding only those CHs with high f- value. Evidently, the proposed UCFLEE protocol can achieve effective equilibrium of energy consumption, keeping the majority of nodes alive to a greater extent than the related protocol.

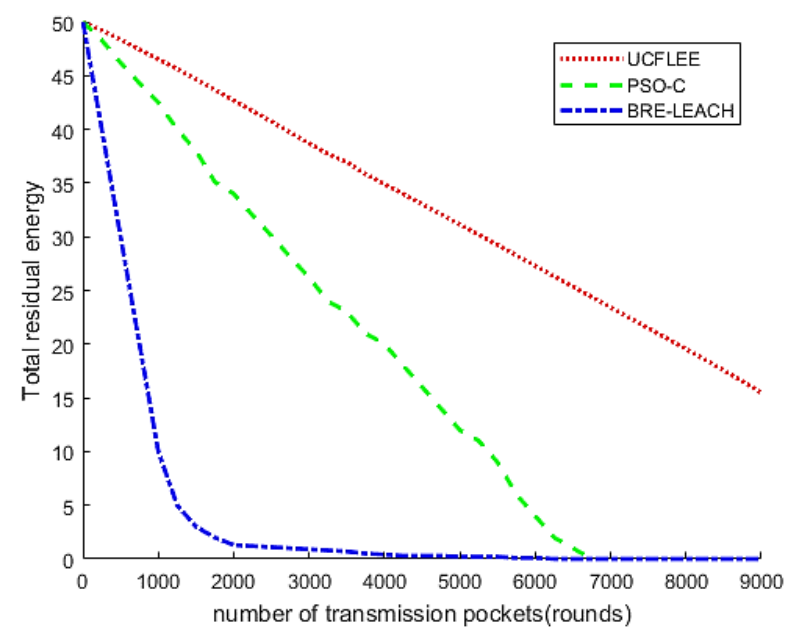

Figure 6. The total residual energy for for all of the protocols the three protocols

\section{CONCLUSION}

A new protocol for WSNs called UCFLEE has been presented in this paper. The UCFLEE protocol considers the issues of minimising energy dissipation and load balancing. The UCFLEE protocol contributed to minimising the hot spot problems and facilitated the identification of efficient routing to the base station. The concepts of altering and selecting cluster heads are employed to decrease energy dissipation and to balance the nodal loads. The threshold concept is engaged to enable all nodes to consume an equivalent amount of energy. The extensive experimentations confirm that the UCFLEE scheme significantly decreases the node's energy consumption, while enhancing network lifetime to a greater extent than the previous protocols. 


\section{REFERENCES}

[1] Z. Fei, B. Li, S. Yang, C. Xing, H. Chen, and L. Hanzo, "A survey of multi-objective optimization in wireless sensor networks: metrics, algorithms, and open problems," IEEE Communications Surveys \& Tutorials, vol. 19, no. 1, pp. 550-586, 2017, doi: 10.1109/COMST.2016.2610578

[2] J. Yan, M. Zhou, and Z. Ding, "Recent advances in energy-efficient routing protocols for wireless sensor networks: A review," IEEE Access, vol. 4, pp. 5673-5686, 2016, doi: 10.1109/ACCESS.2016.2598719.

[3] P. K. Mishra and S. K. Verma, "FFMCP: feed-forward multi-clustering protocol using fuzzy logic for wireless sensor networks (WSNs)," Energies, vol. 14, no. 10, p. 2866, May 2021, doi: 10.3390/en14102866.

[4] G. Anastasi, M. Conti, M. Di Francesco, and A. Passarella, "Energy conservation in wireless sensor networks: A survey," Ad Hoc Networks, vol. 7, no. 3, pp. 537-568, May 2009, doi: 10.1016/j.adhoc.2008.06.003.

[5] A. A. Alkathmawee, L. Feng, and I. S. Alshawi, "Prolonging the lifetime of wireless sensor networks using LPA-star search algorithm," Indonesian Journal of Electrical Engineering and Computer Science, vol. 1, no. 2, p. 390, Feb. 2016, doi: 10.11591/ijeecs.v1.i2.pp390-398.

[6] S. Randhawa and S. Jain, "MLBC: multi-objective load balancing clustering technique in wireless sensor networks," Applied Soft Computing, vol. 74, pp. 66-89, Jan. 2019, doi: 10.1016/j.asoc.2018.10.002.

[7] S. E. Khediri, N. Nasri, R. U. Khan, and A. Kachouri, "An improved energy efficient clustering protocol for increasing the life time of wireless sensor networks," Wireless Personal Communications, vol. 116, no. 1, pp. 539-558, Jan. 2021, doi: 10.1007/s11277-020-07727-y.

[8] A. S. Rostami, M. Badkoobe, F. Mohanna, H. Keshavarz, A. A. R. Hosseinabadi, and A. K. Sangaiah, "Survey on clustering in heterogeneous and homogeneous wireless sensor networks," The Journal of Supercomputing, vol. 74, no. 1, pp. 277-323, Jan. 2018, doi: 10.1007/s11227-017-2128-1.

[9] C. Donati-Martin, "Stochastic integration with respect to q Brownian motion," Probability Theory and Related Fields, vol. 125, no. 1, pp. 77-95, Jan. 2003, doi: 10.1007/s00440-002-0224-4.

[10] W. B. Heinzelman, A. P. Chandrakasan, and H. Balakrishnan, "An application-specific protocol architecture for wireless microsensor networks," IEEE Transactions on Wireless Communications, vol. 1, no. 4, pp. 660-670, Oct. 2002, doi: 10.1109/TWC.2002.804190.

[11] N. M. A. Latiff, C. C. Tsimenidis, and B. S. Sharif, "Energy-aware clustering for wireless sensor networks using particle swarm optimization," in 2007 IEEE 18th International Symposium on Personal, Indoor and Mobile Radio Communications, 2007, pp. 1-5, doi: 10.1109/PIMRC.2007.4394521.

[12] H. Liang, S. Yang, L. Li, and J. Gao, "Research on routing optimization of WSNs based on improved LEACH protocol," EURASIP Journal on Wireless Communications and Networking, vol. 2019, no. 1, p. 194, Dec. 2019, doi: 10.1186/s13638-0191509-y.

[13] A. Rozas and A. Araujo, "An application-aware clustering protocol for wireless sensor networks to provide QoS management," Journal of Sensors, vol. 2019, pp. 1-11, Sep. 2019, doi: 10.1155/2019/8569326.

[14] E. Alnawafa and I. Marghescu, "New energy efficient multi-hop routing techniques for wireless sensor networks: static and dynamic techniques," Sensors, vol. 18, no. 6, p. 1863, Jun. 2018, doi: 10.3390/s18061863.

[15] K. Cengiz and T. Dag, "Multi-hop low energy fixed clustering algorithm (M-LEFCA) for WSNs," in 2016 IEEE 3rd International Symposium on Telecommunication Technologies (ISTT), pp. 31-34, Nov. 2016, doi: 10.1109/ISTT.2016.7918080.

[16] M. Selvi, C. Nandhini, K. Thangaramya, K. Kulothungan, and A. Kannan, "HBO based clustering and energy optimized routing algorithm for WSN," in 2016 Eighth International Conference on Advanced Computing (ICoAC), Jan. 2017, pp. 89-92, doi: 10.1109/ICoAC.2017.7951751.

[17] I. Daanoune, A. Baghdad, and A. Balllouk, "BRE-LEACH: A new approach to extend the lifetime of wireless sensor network," in 2019 Third International Conference on Intelligent Computing in Data Sciences (ICDS), Oct. 2019, pp. 1-6, doi: 10.1109/ICDS47004.2019.8942253.

[18] S. K. Singh, P. Kumar, and J. P. Singh, "Correction to: An energy efficient protocol to mitigate hot spot problem using unequal clustering in WSN," Wireless Personal Communications, vol. 102, no. 2, pp. 2091-2091, Sep. 2018, doi: 10.1007/s11277-0185921-0.

[19] A. A. Jasim, M. Y. I. Idris, S. R. Bin Azzuhri, N. R. Issa, M. T. Rahman, and M. F. B. Khyasudeen, "Energy-efficient wireless sensor network with an unequal clustering protocol based on a balanced energy method (EEUCB)," Sensors, vol. 21, no. 3, p. 784, Jan. 2021, doi: 10.3390/s21030784.

[20] N. Islam, S. Dey, and S. Sampalli, "Energy-balancing unequal clustering approach to reduce the blind spot problem in wireless sensor networks (WSNs)," Sensors, vol. 18, no. 12, p. 4258, Dec. 2018, doi: 10.3390/s18124258.

[21] A. A. Alkadhmawee, M. A. Altaha, and W. Mahmood Lafta, "Unequal clustering algorithm with IDA* multi-hop routing to prevent hot spot problem in WSNs," Indonesian Journal of Electrical Engineering and Computer Science, vol. 20, no. 1, p. 445, Oct. 2020, doi: 10.11591/ijeecs.v20.i1.pp445-453.

[22] Z. Saletic, D. M. Velasevic, and N. E. Mastorakis, "Analysis of basic defuzzification techniques," in Proceedings of the 6th WSES international multiconference on circuits, systems, communications and computers, 2002, pp. 247-252.

[23] R. E. Korf, "Depth-first iterative-deepening," Artificial Intelligence, vol. 27, no. 1, pp. 97-109, Sep. 1985, doi: 10.1016/00043702(85)90084-0.

[24] K. Khantanapoka and K. Chinnasarn, "Pathfinding of 2D \&\#x00026; 3D game real-time strategy with depth direction A\&\#x2217; algorithm for multi-layer," in 2009 Eighth International Symposium on Natural Language Processing, Oct. 2009, pp. 184-188, doi: 10.1109/SNLP.2009.5340922.

[25] T. Cazenave, "Partial move A*," in 2010 22nd IEEE International Conference on Tools with Artificial Intelligence, Oct. 2010, pp. 25-31, doi: 10.1109/ICTAI.2010.79.

[26] G. Smaragdakis, I. Matta, and A. Bestavros, "SEP: A stable election protocol for clustered heterogeneous wireless sensor networks Heterogeneous WSN o Nodes have different energy levels," in Second International Workshop on Sensor and Actor Network Protocols and Applications (SANPA 2004), 2004, pp. 251-261. 


\section{BIOGRAPHIES OF AUTHORS}

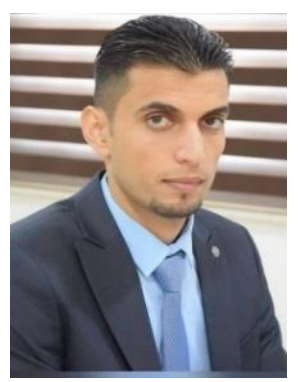

Mohammed Adnan Altaha (iD 81 SC P Complete his Bachelor's degree in Computer Science from the College of Education for Pure Science, University of Basrah, Basrah, Iraq (2009), completed his master's degree in Computer Science from the college of Science, University of Basrah, Basrah, Iraq (2018), currently works as a lecture. Assist. in the College of Veterinary, University of Basrah, Basrah, Iraq, published several scientific researches in computer science. He can be contacted at email: mohammed.altaha@uobasrah.edu.iq.

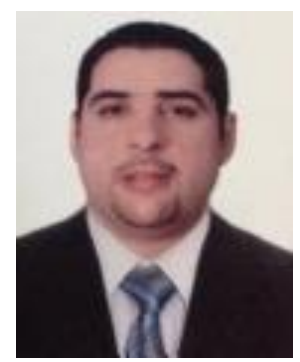

Ahmed Adil Alkadhmawee (D) SC P is a lecturer at Basrah University, Iraq. He holds an M. Sc degree in Computer Engineering at Huazhong University of Science and Technology in China. He is research areas are Wireless Sensor Network, Machine Learning and Deep Learning. He has authored more than 11 publications: 1 proceeding and 10 journals, with $3 \mathrm{H}$ index and more than 19 citations. He can be contacted at email: ahmedadel@ uobasrah.edu.iq.

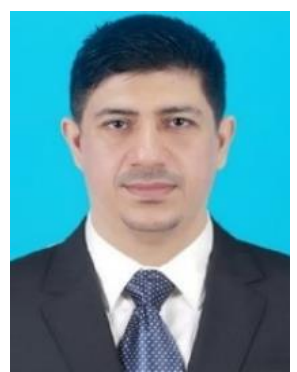

Wisam Mahmood Lafta (D) SA SC P Was born in Baghdad, Iraq. Received a BSc in computer science from the University of Technology; the MSc at Huazhong University of Science and Technology in China. He is currently a faculty member in the computer science department, University of Technology, Baghdad, Iraq. He has some important published papers in international journals and a reviewer at some international journals. He can be contacted at email: wisam.m.lafta@uotechnology.edu.iq. 